\title{
Medical students' satisfaction with clinical clerkship and its relationship with professional self-concept
}

\author{
Ji Hye Yu', Su Kyung Lee ${ }^{2}$, Miran Kim', Su Jin Chae ${ }^{3}$, Ki Young Lim ${ }^{4}$ and Ki Hong Chang ${ }^{1}$ \\ ${ }^{1}$ Office of Medical Education and ${ }^{2}$ Ajou Center for Clinical Excellence, Ajou University School of Medicine, \\ Suwon, ${ }^{3}$ Department of Medical Education, Catholic Kwandong University College of Medicine, Incheon, and \\ ${ }^{4}$ Department of Psychiatry, Ajou University School of Medicine, Suwon, Korea
}

Purpose: Medical students construct their identity as a student physician through clinical clerkship. However, there is a lack of research on the effect of clinical clerkship on professional self-concept formation. The aim of this study is to analyze and ascertain the relationship between medical students' satisfaction with clinical clerkship and professional self-concept.

Methods: This investigation studied 84 third- and fourth-year medical students enrolled in the Ajou University School of Medicine and Graduate School of Medicine. Study measures tools included satisfaction with clinical clerkship and professional self-concept measurement. For data analyses, a descriptive analysis of the research variable characteristics was applied, gender differences in variables by years of medical school were analyzed with t-tests, and correlation analysis was used to check for relationships between variables.

Results: We found no statistically significant differences between satisfaction with clinical clerkship with respect to medical school year and gender. While professional self-concept did not show significant differences by year of medical school, we observed statistically significant differences by gender with respect to the subscales of professional practice and communication factor. In addition, satisfaction with clinical clerkship and professional self-concept demonstrated statistically significant positive correlation. The present research was able to confirm that there exists a correlation between medical students' clinical clerkship experience and professional self-concept formation.

Conclusion: Our study outcomes shows that provision of positive assistance as a measure to enhance satisfaction with clinical clerkship via the curriculum and environmental improvement is envisaged to lead to medical students' professional self-concept formation.

Key Words: Clinical clerkship, Medical schools, Professional self-concept

\section{Introduction}

Current medical school education to date has been directed towards rearing physicians who are skilled in both medical and clinical fields. However, emerging recent trends of medical education have leaned towards not only imparting knowledge and clinical skills but concentrating as well on medical students' role development as physicians with respect to professional self-concept. Professional self-concept refers to how a person who is a member of a specific group perceives his/her selfprofessionalism and beliefs, values, motivation, and $\mathrm{ex}^{-}$ periences, which gradually becomes internalized to affect
Received: November 6, 2019 • Revised: February 11, 2019 • Accepted: March 6, 2019 Corresponding Author: Miran Kim (https://orcid.org/0000-0001-5553-5334) Office of Medical Education, Ajou University School of Medicine, 164 World cup-ro, Yeongtong-gu, Suwon 16499, Korea

Tel: +82.31.219.5250 Fax: +82.31.219.5245 email: kmr5300@ajou.ac.kr
Korean J Med Educ 2019 Jun; 31(2): 125-133.

https://doi.org/10.3946/kjme.2019.124

eISSN: 2005-7288

(C) The Korean Society of Medical Education. All rights reserved. This is an open-access article distributed under the terms of the Creative Commons Attribution Non-Commercial License (http:// creativecommons.org/licenses/by-nc/3.0/), which permits unrestricted non-commercial use, distribution, and reproduction in any medium, provided the original work is properly cited. 
thoughts, behavior, and emotions [1,2]. On this basis, a physician's professional self-concept may be defined as the subjective self-acknowledgement of the characteristics of a physician possessing self-professionalism and clinical ability. Medical students are imparted a regular education curriculum and hidden-curriculum education by the medical school and internalize the characteristics, values, and norms of a physician, and hence gradually develop the professional self-concept of a physician [3].

Medical students' professional self-concept is important because it influences post-graduate training and clinical clerkship [4]. Moreover, professional self-concept helps resolve psychological problems such as burnout [5], and is especially noteworthy as playing the core role in building a specialist physician's ability in his/her chosen specialist field after entry [6]. Self-concept contains dynamic characteristics such as interactions with other persons in an established, varied social environment and context [7]. In other words, professional self-concept of medical students is formed through diverse situations and relationships, such as the lectures and clinical clerkship programs that they experience. In particular, it has been observed in many previous studies that among the numerous variables that impact medical students' professional self-concept formation, clinical clerkship is suggested to be a major factor $[8,9]$.

Medical students apply their learned medical theories and knowledge to real medical situations during their clerkship course, and subsequently by realizing their self-identity as a medical student and then a physician [10]. Through encounters with clinical experience, professional self-concept formation is established by meeting face to face with patients, and via discussions with and feedback from clerkship course supervising residents and faculty $[8,10]$. Also, the clerkship course offers an opportunity for medical students to shape diverse inter- personal relationships with fellow students, faculty, patients, and co-workers such as nurses and nonmedical hospital employees, which brings about professional self-concept formation [9]. As a result, it may be assumed that medical students who attain higher degrees of satisfaction during clinical clerkship also have high levels of professional self-concept. However, despite the impact of these factors, research that has demonstrated positive effects of the clerkship course on professional self-concept formation is as yet inadequate. Therefore, in this study the authors aim to analyze results as regards medical students' clerkship satisfaction and professional self-concept, and ascertain the relationship between the variables, on the supposition that students' clerkship will affect their professional self-concept.

The main research aims and topics are as follows: First, what is the extent/level of clinical clerkship satisfaction and professional self-concept according to gender and year among medical school students? Second, what is the relationship between the extent/level of clinical clerkship satisfaction and professional selfconcept among medical school students?

\section{Methods}

\section{Participants}

This research investigated 86 third- and fourth-year medical students attending the Ajou University School of Medicine, Suwon, Korea, among whom 84 responded to the questionnaire. Data was collected through an online survey from February 1 to 14, 2018. This study was approved by the Institutional Review Board of Ajou University Hospital (ethics consent no., AJIRB-SBRSUR-17-471). 


\section{Measures}

\section{1) Satisfaction with clinical clerkship}

The nursing students' satisfaction with clinical clerkship measurement tool, which was developed by Cho and Kang [11] and later modified and supplemented by Lee et al. [12], was employed to ascertain the satisfaction with clinical clerkship of medical students in this study. The above measurement tool was tailored for the medical students involved by omitting the "clinical clerkship of nursing patients according to nursing process" question, which left 30 questions on the survey. Subscales of variables comprised three questions on the practice course, five on practice contents, nine on practice instruction, seven on the practice environment, three on practice hours, and three on clinical evaluation. Each question was scored on a 5-point Likert scale, and a higher number of points indicated higher levels of satisfaction with clinical clerkship. The derived Cronbach's $\alpha$ was 0.948 for satisfaction with clinical clerkship.

\section{2) Professional self-concept}

In order to measure professional self-concept, the professional self-concept of nurses developed by Arthur [13] was modified and revised to fit the self-concept for medical doctors. This professional self-concept modification consists of three fields: professional practice, job satisfaction, and interpersonal communication. Professional practice includes leadership ability over other persons, flexibility that entails utilizing one's situation to the utmost, and skills that permit competent work performance. Job satisfaction is defined as the degree to which one experiences satisfaction and joy in performing one's job duties, while interpersonal communication is characterized by empathy and open-mindedness in interpersonal relationships. This measurement consists of a total of 27 questions: professional practice $(n=16)$, satisfaction $(n=7)$, and communication $(n=4)$. Each ques ${ }^{-}$ tion was scored on a 4-point Likert scale, ranging from 'strongly do not agree' (1 point) to 'strongly agree' (4 points), and a higher number of points is deemed as being correlated with higher levels of professional selfconcept. The Cronbach's $\alpha$ value for professional selfconcept in this study was 0.896 .

\section{Analysis}

Descriptive statistics of the variables of the current research were calculated including mean \pm standard deviation. In order to evaluate the different variables according to gender and medical school year, a Student t-test was performed. Relationships between variables were determined by using Pearson's correlation analysis.

\section{Results}

\section{Descriptive statistics of the scales}

The results of the general tendency analysis centered on the applied variables of our study subjects are shown in Table 1. In the analysis of the satisfaction with clinical clerkship according to sub-factors, the clerkship course $(3.82 \pm 0.67)$ factor showed the highest degree of satisfaction, followed by, in decreasing order: clerkship environment (3.61 \pm 0.66$)$, clerkship instruction (3.56 $\pm 0.67)$, clerkship contents $(3.49 \pm 0.55)$, clerkship hours (3.41 \pm 0.87$)$, and clerkship evaluation (3.08 \pm 0.92$)$. Among professional self-concept variables the values were, in decreasing order for professional practice (2.97 \pm 0.48$)$, degree of satisfaction $(2.96 \pm 0.52)$, and physician communication $(2.88 \pm 0.46)$. The professional practice subscales of variables were, in decreasing order: flexibility (2.99 \pm 0.48$)$, skill $(3.00 \pm 0.54)$, and leadership $(2.91 \pm 0.53)$.

Comparison of the satisfaction with clinical clerkship 


\begin{tabular}{llc}
\hline Table 1. Descriptive Statistics of Ratings by Scales & \\
\hline \multicolumn{1}{c}{ Scales } & & Subscales \\
\hline Satisfaction with clinical clerkship & & $3.49 \pm 0.56$ \\
& Course & $3.82 \pm 0.67$ \\
& Contents & $3.49 \pm 0.55$ \\
& Instruction & $3.56 \pm 0.67$ \\
& Environment & $3.61 \pm 0.66$ \\
Professional self-concept & Hours & $3.41 \pm 0.87$ \\
& Evaluation & $3.08 \pm 0.92$ \\
& & $2.94 \pm 0.35$ \\
& Professional practice & $2.97 \pm 0.48$ \\
& Leadership & $2.91 \pm 0.53$ \\
& Flexibility & $2.99 \pm 0.48$ \\
& Skill & $3.00 \pm 0.54$ \\
& Satisfaction & $2.96 \pm 0.52$ \\
& Communication & $2.88 \pm 0.46$ \\
\hline
\end{tabular}

Table 2. Satisfaction Levels in Clerkship Experience by Gender and Year of Study ( $N=84)$

\begin{tabular}{|c|c|c|c|c|c|c|c|}
\hline Variable & Course & Contents & Instruction & Environment & Hours & Evaluation & Total \\
\hline \multicolumn{8}{|l|}{ Gender } \\
\hline Male & $3.75 \pm 0.71$ & $3.52 \pm 0.58$ & $3.59 \pm 0.67$ & $3.70 \pm 0.67$ & $3.47 \pm 0.91$ & $3.15 \pm 0.92$ & $3.53 \pm 0.58$ \\
\hline Female & $3.95 \pm 0.57$ & $3.43 \pm 0.49$ & $3.50 \pm 0.68$ & $3.46 \pm 0.63$ & $3.30 \pm 0.79$ & $2.93 \pm 0.93$ & $3.43 \pm 0.54$ \\
\hline t-value & -1.33 & 0.76 & 0.57 & 1.64 & 0.84 & 1.04 & 0.79 \\
\hline \multicolumn{8}{|l|}{ Year } \\
\hline Third year & $3.75 \pm 0.71$ & $3.44 \pm 0.62$ & $3.55 \pm 0.71$ & $3.62 \pm 0.72$ & $3.58 \pm 0.75$ & $3.01 \pm 0.86$ & $3.49 \pm 0.59$ \\
\hline Fourth year & $3.89 \pm 0.62$ & $3.54 \pm 0.47$ & $3.57 \pm 0.63$ & $3.62 \pm 0.61$ & $3.24 \pm 0.96$ & $3.14 \pm 0.98$ & $3.50 \pm 0.54$ \\
\hline t-value & -0.93 & -0.79 & -0.20 & 0.05 & 1.82 & -0.67 & -0.06 \\
\hline
\end{tabular}

Data are presented as mean \pm standard deviation.

\begin{tabular}{|c|c|c|c|c|c|c|c|}
\hline \multirow{2}{*}{ Variable } & \multicolumn{4}{|c|}{ Professional practice } & \multirow{2}{*}{ Satisfaction } & \multirow{2}{*}{ Communication } & \multirow{2}{*}{ Total } \\
\hline & Leadership & Flexibility & Skill & Total & & & \\
\hline \multicolumn{8}{|l|}{ Gender } \\
\hline Male & $3.00 \pm 0.57$ & $3.09 \pm 0.48$ & $3.08 \pm 0.54$ & $3.06 \pm 0.50$ & $2.97 \pm 0.53$ & $2.80 \pm 0.48$ & $2.94 \pm 0.36$ \\
\hline Female & $2.74 \pm 0.42$ & $2.80 \pm 0.41$ & $2.84 \pm 0.52$ & $2.80 \pm 0.38$ & $2.96 \pm 0.50$ & $3.02 \pm 0.37$ & $2.92 \pm 0.34$ \\
\hline t-value & $2.13^{*}$ & $2.71^{* *}$ & 1.92 & $2.42^{*}$ & 0.12 & $-2.12^{*}$ & 0.23 \\
\hline \multicolumn{8}{|l|}{ Year } \\
\hline Third year & $2.89 \pm 0.58$ & $2.96 \pm 0.46$ & $3.03 \pm 0.55$ & $2.96 \pm 0.50$ & $2.89 \pm 0.54$ & $2.81 \pm 0.41$ & $2.89 \pm 0.35$ \\
\hline Fourth year & $2.93 \pm 0.49$ & $3.02 \pm 0.49$ & $2.98 \pm 0.54$ & $2.98 \pm 0.46$ & $3.04 \pm 0.49$ & $2.94 \pm 0.50$ & $2.99 \pm 0.35$ \\
\hline t-value & -0.37 & -0.53 & 0.44 & 0.15 & -1.36 & -1.33 & -1.30 \\
\hline
\end{tabular}

Data are presented as mean \pm standard deviation.

${ }^{*} p<0.05,{ }^{* *} p<0.01$.

by gender and medical school year are shown in Table

2. We observed no statistically significant difference in the factor of satisfaction with clinical clerkship with regard to gender or year of medical school.

We analyzed the level of professional self-concept with respect to gender and medical school year and the results are displayed in Table 3. It was found that the analysis of the professional self-concept subscales of variables by gender showed statistically significant differences for professional practice and physician com- 


\begin{tabular}{|c|c|c|c|c|c|c|c|}
\hline \multirow{2}{*}{ Variable } & \multicolumn{4}{|c|}{ Professional practice } & \multirow{2}{*}{ Satisfaction } & \multirow{2}{*}{ Communication } & \multirow{2}{*}{$\begin{array}{l}\text { Professional } \\
\text { self-concept }\end{array}$} \\
\hline & Total & Leadership & Flexibility & Skill & & & \\
\hline Course & $0.29 * *$ & 0.21 & $0.33^{* *}$ & $0.27^{*}$ & $0.31^{* *}$ & 0.16 & $0.35^{* *}$ \\
\hline Contents & $0.35^{* *}$ & $0.26^{*}$ & $0.40^{* *}$ & $0.31^{* *}$ & $0.44^{* *}$ & $0.22^{*}$ & $0.47^{* *}$ \\
\hline Instruction & $0.33^{* *}$ & $0.26^{*}$ & $0.38^{* *}$ & $0.29 * *$ & $0.37^{* *}$ & 0.10 & $0.37^{* *}$ \\
\hline Environment & $0.43^{* *}$ & $0.38 * *$ & $0.42^{* *}$ & $0.39 * *$ & $0.23^{*}$ & 0.08 & $0.34^{* *}$ \\
\hline Hours & $0.43^{* *}$ & $0.36^{* *}$ & $0.46^{* *}$ & $0.38^{* *}$ & $0.29^{* *}$ & 0.11 & $0.38^{* *}$ \\
\hline Evaluation & $0.25^{* *}$ & 0.19 & $0.32^{* *}$ & 0.20 & 0.07 & -0.03 & 0.13 \\
\hline Satisfaction with clinical clerkship & $0.44^{* *}$ & $0.35^{* *}$ & $0.49^{* *}$ & $0.39 * *$ & $0.34^{* *}$ & 0.12 & $0.42^{* *}$ \\
\hline
\end{tabular}

${ }^{*} \mathrm{p}<0.05,{ }^{* *} \mathrm{p}<0.01$.

munication, and also that within professional practice there were significant differences for leadership and flexibility, in both of which traits male medical students showed statistically significantly higher scores than did female medical students. In contrast, physician communication measures revealed that female medical students scored statistically significant higher than male medical students. There was no significant difference in professional self-concept with regard to medical school year.

\section{Correlations between professional self- concept and satisfaction with clinical clerk- ship}

The analysis of data concerning the relationship between professional self-concept and satisfaction with clinical clerkship is shown in Table 4. The results showed a statistically significant positive relationship between professional self-concept and satisfaction with clinical clerkship $(r=0.42, p<0.01)$. Among the three professional self-concept factors, no statistically significant relationship was determined between physician communication and degree of clerkship satisfaction.

Assessment of the subscales of satisfaction with clinical clerkship shows that the highest correlation of professional self-concept was with practice contents $(\mathrm{r}=0.47, \mathrm{p}<0.01)$ followed by, in decreasing order: practice hours $(\mathrm{r}=0.38, \mathrm{p}<0.01)$, practice instruction $(\mathrm{r}=0.37, \mathrm{p}<0.01)$, practice course $(\mathrm{r}=0.35, \mathrm{p}<0.01)$, and practice environment $(\mathrm{r}=0.34, \mathrm{p}<0.01)$. We did not observe any significant relationship between practice evaluation and professional self-concept.

\section{Discussion}

The main objective of the current research was to investigate the levels of satisfaction with clinical clerkship and professional self-concept among medical students who have experienced clinical clerkship courses and to ascertain the relationship between satisfaction with clinical clerkship and professional self-concept. The degree of satisfaction with clinical clerkship and professional self-concept of the participating medical students were determined first. Our results show that the participating students' level of satisfaction with clinical clerkship had a mean of 3.49 or greater on the 5-point Likert scale. In the majority of clinical aspects which include clerkship practice course, environment, instruction, contents, and hours, the responses to the provided questionnaires showed relatively strong satisfaction levels among the students, but the degree of clinical evaluation satisfaction was relatively low. It appears that the current clerkship course program's aims and contents need to be scrutinized and analyzed with respect to pertinent factors so as to establish the most appropriate 
and fair measurement of assessment standards for questionnaire items.

The professional self-concept score was 2.93 on a 4-point Likert scale, and among the professional self-concept subscales of variables, professional practice and degree of satisfaction showed relatively similar scores, while physician communication scored low in comparison. Professional self-concept has been conceived as arising from a process of adaptation to the direct experience of medical situations [14]. The subjects of this study were fifth-year and sixth-year (graduate year) medical students who have undergone 1-2 years of clinical hospital clerkship, and it is thought that the clinical clerkship would affect the constitution of professional self-concept among medical students and physicians. The medical students were able to cultivate, achieve and exhibit professional practice abilities such as skills and, leadership during their respective medical clerkships that led to flexibility and job competency in adequately responding to clinical situations, and ultimately attain satisfaction in their academic course to become physicians. In a study by Kang [15], who questioned dental students regarding their levels of satisfaction, it was observed that physician communication, professional practice, and degree of satisfaction, in decreasing order, were significant factors, and another study of nursing students by Shin and Cho [16] indicated that satisfaction levels were highest for physician communication, professional practice, and degree of satisfaction, in descending order. These past results are contrary to our observations, in which physician communication appeared as the lowest level of satisfaction, which may indicate relatively inadequate openmindedness and empathy of medical students towards patients. Continuous education is considered essential so that through their clinical clerkships, medical students will be capable not only of compassion for their patients but also of understanding their many co-workers in the medical environment such as nurses and other hospital staff and employees, later as a physician. Also, the faculty and residents in charge of clinical clerkship education supervision will be seen as examples and role models. In fact, students are reported to have selfconfidence in performing medical interviews through participating in the professor's outpatient care and directly observing patients [17]. The major objective of medical school education for medical students is not only transferring medical knowledge and assimilation of clinical skills but also nurturing empathy, altruism, and integrity such that a physician proffers patient-centered medical service $[18,19]$. Therefore, it is deemed essential that the education of medical students be directed to inculcating these qualities during the clinical clerkship course curriculum.

Among the professional self-concept subscales of variables, leadership, flexibility, and physician communication were factors that showed statistical differences by gender. Male medical students had self-acknowledged relatively higher leadership and flexibility scores than female medical students, while on the other hand physician communication was lower among male students. The above results may indicate that male medical students have greater leadership abilities than female medical students, and that the leadership responsibilities of male students that ensures when assuming the role of a leader are less burdensome, but that male students also experience difficulty in forming affective bonds and communicating with fellow students or patients. Such differences by gender may be explained by the social role theory of gender differences [20]. Males tend to be more socially dominant, independent, and strong willed, with a concomitant focus on task-orientated tasksolving in the job environment and a tendency to focus on the problem at hand to resolve the issue. In contrast, 
female students are characterized by expressing sensitivity, politeness, hospitality, and empathy while having a greater regard for possible issues pertaining to interpersonal relationships. Also, female students feel strain when the focus of attention is on themselves in the job environment, more easily accept other persons' instructions, and make greater efforts to concentrate on resolving interpersonal relationship problems.

This gender disparity formation is observed more frequently in Western societies than in East Asian cultures and has also been demonstrated among medical school students. In a study of medical students conducted by the UCLA medical school, it was shown that fewer female medical students assumed leadership of small groups than their male counterparts, and the number of male medical students who self-volunteered for leadership positions far outnumbered the number of female medical students who did so. In view of the present era where the proportion of female medical students has increased dramatically compared to the past, there still exist discrepancies with respect to gender based stereotype both in the West and in East Asia [21].

In the current study we were able to observe a significantly positive relationship between clinical clerkship degree of satisfaction and professional selfconcept. This relationship indicates that higher clerkship satisfaction is associated with the enhancement of professional self-concept. A medical students' formation of professional identity as a medical student and later as a physician is shaped during the experience of the dynamics in varied circumstances and relationships that occur in a medical environment situation [22]. It has also been stated that in order to heighten the professional self-concept that is reflected in medical students' professional identity, there is a basic need to strengthen the degree of satisfaction with clinical clerkship to attain a high-quality clinical clerkship education [23].
Numerous studies have addressed the issue and impact of professional identity as a physician, but there is a paucity of analytic data pertaining to the formation of professional identity and its association with relevant variables. The present study was conducted to empirically explore the significance of professional identity for the role of future physicians as a basis for elucidating factors that may influence professional self-concept, and was also aimed at substantiating the analysis of its relationship with satisfaction with clinical clerkship. The results demonstrate that medical students' satisfaction with the clinical clerkship experience is associated with the formation of professional self-concept among medical students. In addition, the analysis of the correlation between satisfaction with clinical clerkship and professional self-concept confirms that satisfaction with clinical clerkship was a factor affecting the medical professional's self-concept formation process. Based on the above observations and findings the following are suggested by the current authors.

First, this study analyzed the level of satisfaction with clinical clerkship of medical students for the clinical clerkship program as a whole. However, since there exist differences in the contents and environment of clerkships between departments, a more detailed collection of data is called for. If this is possible, then a concrete plan to identify the departments with a high degree of satisfaction, should lead to a higher degree of clinical clerkship satisfaction.

Second, there is a need for studies that examine the factors related to professional self-concept development among physicians. There is also need to review not only knowledge and medical skill but also the inculcation of the values, norms, and virtues of physicians. If a detailed and practical concept of professional self-concept variables is constituted then research to examine this issue systematically will be possible. 


\section{ORCID:}

Ji Hye Yu: https://orcid.org/0000-0002-8039-6580;

Su Kyung Lee: https://orcid.org/0000-0003-1747-8329;

Miran Kim: https://orcid.org/0000-0001-5553-5334;

Su Jin Chae: https://orcid.org/0000-0003-3060-8933;

Ki Young Lim: https://orcid.org/0000-0003-0256-4240;

Ki Hong Chang: https://orcid.org/0000-0002-3627-5642

Acknowledgements: None.

Funding: No funding was obtained for this study.

Conflicts of interest: No potential conflict of interest relevant to this article was reported.

Author contributions: Conceived the study concept and design: YJH, KMR; analyzed and interpreted the data, draft the manuscript: YJH; acquired the data: LSK; assisted in interpretation the manuscript: $\mathrm{CKH}$; revised the manuscript: LKY; assisted in interpretation of the data, revised the manuscript: CSJ; and critically revised the manuscript and supervised the study: KMR.

\section{References}

1. Wald HS, Anthony D, Hutchinson TA, Liben S, Smilovitch M, Donato AA. Professional identity formation in medical education for humanistic, resilient physicians: pedagogic strategies for bridging theory to practice. Acad Med. 2015;90(6):753-760.

2. Crossley J, Vivekananda-Schmidt P. The development and evaluation of a Professional Self Identity Questionnaire to measure evolving professional self-identity in health and social care students. Med Teach. 2009;31(12):e603-e607.

3. Moss JM, Gibson DM, Dollarhide CT. Professional identity development: a grounded theory of transformational tasks of counselors. J Couns Dev. 2014;92(1):3-12.

4. Slay HS, Smith DA. Professional identity construction: Using narrative to understand the negotiation of pro- fessional and stigmatized cultural identities. Hum Relat. 201 1;64(1):85-107.

5. Cruess RL, Cruess SR, Boudreau JD, Snell L, Steinert Y. Reframing medical education to support professional identity formation. Acad Med. 2014;89(11):1446-1451.

6. Papadakis MA, Teherani A, Banach MA, et al. Disciplinary action by medical boards and prior behavior in medical school. N Engl J Med. 2005;353(25):2673-2682.

7. Dyrbye LN, Massie FS Jr, Eacker A, et al. Relationship between burnout and professional conduct and attitudes among US medical students. JAMA. 2010;304(11):11731180.

8. Stockhausen LJ. Learning to become a nurse: students' reflections on their clinical experiences. Aust J Adv Nurs. 2005;22(3):8-14.

9. Eisenberg EM. Building a mystery: toward a new theory of communication and identity. J Commun. 2001;51(3): 534-552.

10. Pratt MG, Rockmann KW, Kaufmann JB. Constructing professional identity: the role of work and identity learning cycles in the customization of identity among medical residents. Acad Manag J. 2006;49(2):235-262.

11. Cho KJ, Kang HS. Study on self-concept and satisfaction of clinical clerkship. J Korean Acad Nurs. 1984;14:63-74.

12. Lee SH, Kim SY, Kim JA. Nursing students' image of nurse and satisfaction with clinical practice. J Korean Acad Nurs Adm. 2004;10(2):219-231.

13. Arthur D. Measurement of the professional self-concept of nurses: developing a measurement instrument. Nurse Educ Today. 1995;15(5):328-335.

14. Angel E, Craven R, Denson N. The nurses' self-concept instrument (NSCI): a comparison of domestic and international student nurses' professional self-concepts from a large Australian University. Nurse Educ Today. 2012;32(6):636-640.

15. Kang YJ. A study on the professional self-concept of dental hygiene students and their satisfaction level with 
clinical practice. J Korean Soc Dent Hyg. 2009;9(1):7384.

16. Shin KA, Cho BH. Professional self-concept, critical thinking disposition and clinical competence in nursing students. J Korean Acad Fundam Nurs. 2012;19(1):46-56.

17. Park EW. Comparison of medical students' satisfaction with family medicine clerkships between university hospitals and community hospitals or clinics. Korean J Fam Med. 2016;37(6):340-345.

18. Hirsh DA, Ogur B, Thibault GE, Cox M. "Continuity" as an organizing principle for clinical education reform. N Engl J Med. 2007;356(8):858-866.

19. Mann KV, Ruedy J, Millar N, Andreou P. Achievement of non-cognitive goals of undergraduate medical education: perceptions of medical students, residents, faculty and other health professionals. Med Educ. 2005;39(1): $40-48$.

20. Albanese MA, Snow MH, Skochelak SE, Huggett KN, Farrell PM. Assessing personal qualities in medical school admissions. Acad Med. 2003;78(3):313-321.

21. Eagly AH, Wood W, Diekman AB. Social role theory of sex differences and similarities: a current appraisal. In: Eckes T, Trautner HM, eds. The Developmental Social Psychology of Gender. Mahwah, USA: Lawrence Erlbaum Associates; 2000:123-174.

22. Goldie J. The formation of professional identity in medical students: considerations for educators. Med Teach. 2012;34(9):e64I-e648.

23. Barzansky B, Etzel SI. Medical schools in the United States, 2006-2007. JAMA. 2007;298(9):1071-1077. 